Marquette University

e-Publications@Marquette

College of Nursing Faculty Research and

Publications

Nursing, College of

$10-1-2005$

\title{
Shared Care, Elder and Family Member Skills Used to Manage Burden
}

Margaret Sebern

Marquette University, margaret.sebern@marquette.edu

Accepted version. Journal of Advanced Nursing, Vol. 52, No. 2 (October 2005): 170-179. DOI. (C) 2005 Blackwell Publishing. Used with permission. 


\section{Shared Care, Elder and Family Member Skills Used to Manage Burden}

\section{By Margaret Sebern}

Aim. The aim of this paper is to further develop the construct of Shared Care by comparing and contrasting it to related research, and to show how the construct can be used to guide research and practice.

Background. While researchers have identified negative outcomes for family caregivers caused by providing care, less is known about positive aspects of family care for both members of a family dyad. Understanding family care relationships is important to nurses because family participation in the care of chronically ill elders is necessary to achieve optimal outcomes from nursing interventions. A previous naturalistic inquiry identified a new construct, Shared Care, which was used to describe a family care interaction that contributed to positive care outcomes.

Methods. A literature review was carried out using the databases Medline, CINAHL, and Psych-info and the keywords home care, care receiver, disability, family, communication, decision-making and reciprocity. The results of the review were integrated to suggest how Shared Care could be used to study care difficulties and guide interventions.

Results. The literature confirmed the importance of dyad relationships in family care. Shared Care extended previous conceptualizations of family care by capturing three critical components: communication, decision-making, and reciprocity. Shared Care provides a structure to expand the conceptualization of family care to include both members of a care dyad and account for positive and negative aspects of care.

Conclusions. The extended view provided by the construct of Shared Care offers practitioners and scholars tools to use in the context of our ageing population to improve the effectiveness of family care relationships.

\section{Introduction}

Twenty-three per cent of people in the United States of America (USA) provide unpaid assistance to ill and disabled persons in their place of residence (Donelan et al. 2002). The World Health Organization (2004) expects a 300\% increase in the older population of developing nations, and many of these elders will require assistance from their families. In all countries, the family is a major provider of long-term care, but cannot provide care alone and needs guidance, support, and skills to manage often complex care. 
Giving and receiving care among family members involves complex interactions that can be stressful, with potentially positive and negative consequences for each member of the dyad (Aneshensel et al. 1995, Hooker et al. 1998, Newsom \& Schulz 1998, Liang et al. 2001, Marks et al. 2001). Understanding family care relationships is important to nurses because family participation in the care of chronically ill elders is necessary to achieve optimal outcomes of nursing interventions. Much of the literature about elder family care has focused on a family caregiver to the exclusion of the recipient of care (Gaugler et al. 2002). Less is known about how providing and receiving assistance affects outcomes for both members of the dyad. Reinardy et al. (1999) called for studying family care from the perspectives of both care giver and recipient, especially care for cognitively intact individuals.

The purpose of this paper is to further develop a construct called Shared Care. Shared Care was identified in an earlier naturalistic inquiry (Sebern 1996) to describe aspects of family care relationships from the perspectives of both the care giver and recipient. The aims of this paper are to explain what Shared Care is and how it was identified in a previous naturalistic inquiry; develop the construct of Shared Care by reviewing related research; examine how Shared Care is similar and different from what was previously studied; and to explore how the construct could be used by researchers and practitioners to improve family care relationships.

Family is broadly defined as a social system consisting of at least two members who have ties to each other, are interdependent, have some common history, and share goals (Germino 1991). In this paper, the term 'elder' refers to an adult family member in a health situation requiring assistance, and 'family member' refers to an unpaid caregiver who gives assistance to the elder. This family member is whoever the elder identifies as assisting them with care, and could be a family member, neighbour or friend who is like a family member. The term 'dyad' refers to an elder and the person giving assistance.

\section{What is Shared Care?}

The Shared Care construct (Sebern 1996) was developed by means of a naturalistic inquiry (Lincoln \& Guba 1985) with home healthcare family dyads. The purpose of the naturalistic inquiry was to render a more complete understanding of family interactions with physically disabled elders. Using the hybrid model of concept development (Schwartz-Barcott \& Kim 1993, 2000), Sebern reviewed the health behaviour literature and developed a structured interview guide to explore subjective perceptions and behaviours related to pressure ulcer risk with 21 family dyads. Each of the 21 family dyads participated in four in-depth interviews. Guidelines recommended by Lincoln and Guba (1985) for establishing the credibility and confirmability of 
qualitative data were followed. Credibility was established by conducting interviews in the home, tape recording all interviews, and transcribing them verbatim. In the final meeting, the investigator summarized the content of the interviews with the dyads.

Confirmability of findings was established by maintaining an audit trail so that all results from the analysis of data could be traced back to the narrative data. The audit trail was established by coding the narrative data and writing memos to explain the codes. The elder and caregiver as a unit were analysed by comparing data collected for each individual. Case summaries were completed for each dyad. The focus of the analysis was on ascertaining the way and extent to which they held shared or discrepant perceptions of pressure ulcer risk and responses to perceived risk. As frequently occurs in naturalistic inquiry a new construct was identified and given the name Shared Care, to reflect the interaction between an elder and family member.

This naturalistic inquiry identified three primary components of Shared Care. Shared Care was characterized, first, by communication, particularly communication of symptoms, feelings, advice, and information, which shaped the meaning of the situation for the dyad. Participants in the previous study reported subjective symptoms of skin pain and discomfort to family members. Family members visually assessed the elder's skin and communicated that assessment to the elder. The exchange of thoughts, feelings, and opinions, enabled the members of the dyads to develop an understanding of their shared situation. Adequate communication led to a shared understanding which facilitated decision-making in response to symptoms. A shared understanding of the situation did not always occur. At times there was inadequate communication, disagreement about the meaning of symptoms and how to respond to symptoms. Elders consciously or unconsciously underreported their symptoms. Some elders did not want to bother the caregiver by communicating symptoms. Participants in the previous study made the following statements suggesting inadequate communication, 'I have no one to talk to about how I am feeling' and 'I don't ask for advice about my problems'. These examples of low levels of communication emphasized the importance of communication for Shared Care to occur.

Communication leads to decision-making, the second concept integral to Shared Care. Participants in the previous study used decision-making to exert influence over events and conditions in the elder's environment. Shared Care decision-making was characterized by an elder actively seeking information and being involved in decisions about his/her care. Elder participants in the previous study described decision-making in the following statements, 'When there is something wrong with me I try to get as much information about the problem and what I 
can do', 'When I am not feeling well I decide whether to stay home or go out', and 'When I am not feeling well I decide when to call the doctor'. For some dyads, an elder's evaluation of the situation was the basis of action. In other cases a family member's understanding of the problem was more important in making treatment decisions.

The final component of Shared Care was reciprocity. Communication and decision-making supported reciprocity. Shared Care reciprocity was characterized by dyad behaviours such as empathy, listening, and partnership in managing the illness. Participants in the previous study participated in care within the limits of their abilities. They reported the nature of their reciprocity in the following statements: 'I would feel bad if my family member did not tell me about symptoms that are bothering her', 'If one of us is ill we figure out how to treat the illness together', 'We have a partnership' and 'I listen to my family member'. Thus, communication led to shared understandings and decision-making, which enhanced reciprocity (see Figure 1).

This background definition of Shared Care was expanded by identifying how related research used the concepts of communication, decision-making, and reciprocity, and the outcomes for these studies.

\section{Search methods}

The first step in comparing Shared Care to previous work was to search for studies that examined the concepts of communication, decision-making, and reciprocity in the context of family care research. Medline, CINAHL, and Psych-info databases were used to identify related research. In addition literature an expert believed relevant to Shared Care was reviewed.

Because of the number of published studies on family caregiving across the lifespan, the search was limited to studies published after 1996 and related to care of chronically ill adult elders by unpaid family members. One study published prior to 1996 (Archbold et al. 1990) was included because these researchers developed a tool to measure a construct which is similar to Shared Care, called Mutuality.

None of the identified studies addressed all three components of Shared Care; however, 13 quantitative studies examined the effects of communication, decision-making or reciprocity on elder and/or family member outcomes. An additional four qualitative studies examined the experience of a family carer at home and the breakdown in care that leads to nursing home placement. Table 1 summarizes the quantitative and qualitative studies in which researchers studied the effects of communication, decision-making, and reciprocity on outcomes.

The identified papers were analysed using the following questions. 
- How do researchers conceptually and operationally define communication, decision-making, and reciprocity?

- What are the effects of communication, decision-making and reciprocity on outcomes for both members of the dyad?

- What contextual factors need to be in place for communication, decision-making, and reciprocity to take place?

\section{Findings}

\section{Communication and decision-making}

Several researchers identified communication and agreement between family members as important components of family care relationships. Pruchno et al. (1997a) studied the effects of communication and agreement about problem behaviours on health and well being in a sample of multigenerational family members. The elder's perspective was not included in this study. Problem behaviours were defined as behaviours such as elder pain, trouble breathing, choking, yelling, hearing things that were not there, and embarrassing behaviour. Pruchno et al. created typologies of family members based on high or low agreement about elder problem behaviours. These researchers found that levels of agreement about problem behaviours affected family member burden and depression. Family members who were classified as agreeing about elder behaviours had lower burden and depression, and more caregiver satisfaction and mastery than groups with little agreement. In addition quality of relationships, such as how easy it was to communicate, closeness, and how they get along, correlated with higher levels of agreement about the situation. These authors suggested that high agreement families may interact more frequently, communicate about problems that arise, and try to solve them as a team.

Lyons et al. (2002) and Horowitz et al. (2004) also examined the effects of dyad agreement about family care situations on depression in both elders and family members. The former study by Lyons et al. analysed agreement about difficulties such as availability of emotional and instrumental support (money and finding community resources). These researchers found that family members perceived more difficulties than the elder. The family member's relationship strain, defined as feeling manipulated and depressed, was significantly associated with disagreement about difficulties. A family member's relationship strain predicted his or her own depression and negative health. The latter study by Horowitz and colleagues found that dyad disagreement about an elder's adaptation to vision loss contributed to a depression for both members of the dyad. Researchers for these studies suggested that 
interventions targeting communication skills and promoting a shared understanding of the illness experience may offset dyad disagreement, strain and depression.

Researchers in the previously mentioned studies agreed that communication and agreement about a shared experience were important components of family care. These researchers focused on how communication influenced agreement, and the effects of agreement on psychological well being. Use of the construct Shared Care is more comprehensive in that decision-making and reciprocity are also included as components of the interaction.

Thomas and Ozechowski (2000) conceptualized family systems along three dimensions, adaptability, cohesion, and communication. Communication was measured as high or low levels of family communication. Adaptability was rated along a continuum from rigid to chaotic. Cohesion was scaled as levels of family member engagement in decision-making (disengaged, separated, connected, and enmeshed). Thomas and Ozechowski (2000) found support for the effects of communication and cohesion on family functioning, but no support for adaptability. Specifically these researchers found communication had indirect effects on family functioning through its facilitation of family cohesion in decision-making. Communication and cohesion in decision-making were identified as important components of family functioning, however, Thomas and Ozechowski did not include reciprocity in their model.

Two studies suggested the potential contribution of the characteristics of Shared Care to family member welfare. The studies examined the effects of family environment and care interactions on family member depression (Smerglia \& Deimling 1997, Deimling et al. 2001). These researchers focused on the effects of satisfaction with decision making on depression. Functional impairment was found to have a direct effect on family environment (defined as family adaptability, cohesion, and conflict) and decision-making satisfaction, but no direct effect on family member depression. These researchers found that family environment (adaptability and conflict) predicted decision-making satisfaction. In addition, family adaptability, caregiver type, and decision-making satisfaction predicted depression. These researchers suggested that interventions that enhance decision-making skills may prevent family member depression. In addition to targeting decision-making skills, interventions that enhance communication and reciprocity skills may also be effective in preventing depression.

\section{Reciprocity}

A number of studies were specifically relevant to the Shared Care construct because researchers studied the concept of reciprocity. Several researchers proposed that elders not only receive support from, but also provide substantial assistance to their family member, and these 
acts of reciprocity are important to well being (Archbold et al. 1992, Walker et al. 1992, Davey \& Eggebeen 1998, Newsom 1999, Beach et al. 2000, Liang et al. 2001, Lyons et al. 2002, Wolff \& Agree 2004). These researchers defined reciprocity as enacted support such as advice, aid, affect, and tangible support (e.g. shopping) transmitted through an interpersonal network. The effects of specific patterns of reciprocal exchanges on well being were evaluated. These specific patterns of reciprocity included contingent (support given in response to need), equity (balanced contributions), and over benefiting (receiving more assistance than provided). Reciprocity was measured as objective and subjective perceptions of aid given and received, as a composite measure of support, and as algebraic difference scores between support given and received. These researchers believed that subjective perceptions of reciprocity are more important for well being then actual support exchanged.

\section{Reciprocity effects on the family member}

Researchers have found that care giving can be beneficial to family members. In a longitudinal study, Beach et al. (2000), determined that help provided by a family member to an elder resulted in decreased family member anxiety and depression, as long as there was not physical and emotional strain associated with providing assistance. These researchers suggested that if family members provided assistance and managed potential strain and burden, their overall psychological well being was increased.

Archbold et al. $(1990,1992)$ developed a measure of reciprocity which is part of their Mutuality scale. They defined mutuality as an enduring quality of a relationship with four components shared values, love, shared activities, and reciprocity. These researchers defined reciprocity as giving and accepting physical and emotional help with appreciation. Archbold et al. found that caregivers with low levels of mutuality experienced higher levels of caregiver role strain. Both Sebern (1996) and Archbold et al. conceptualized reciprocity as an important component of family care relationships; however the other components are different.

A number of studies (Kellett 1998, 1999a, 1999b, Kellett \& Mannion 1999) were relevant to the Shared Care construct in that the nature of a family member's experience was studied using hermeneutic analysis. Kellett and colleagues studied the family's care experience at home, during an elder's transition to a nursing home, and in the nursing home. These researchers found that family involvement in care provided the family member with a sense of meaning, purpose, and control. If family members found meaning and purpose in family care, then they searched for new ways of caring for the elder in a nursing home. One theme used by the researchers to describe the family member's experience was self-growth which included 
developing communication skills. Kellett and colleagues' findings extend the understanding of Shared Care, in that Kellett described how family member participation in care and skill-building contributed to their own self worth, meaning, and purpose.

\section{Reciprocity effects on elders}

Researchers studied how the opportunity to reciprocate within a family bolstered the well being of elders (Pruchno et al. 1997b, Davey \& Eggebeen 1998, Newsom \& Schulz 1998, Liang et al. 2001, Wolff \& Agree 2004). These researchers found that elders who gave support to family members had better mental health outcomes (i.e. lower depression). Liang et al. (2001) found that anticipated support, which is expectancy about future support, mediates the effects of social exchanges on well being. These researchers studied the effects of being a recipient of care and found that elder depression was associated with received support, helping distress (mental and emotional strain when helped), and negative interactions (feelings others are being critical of you and prying into personal affairs). Negative reactions to being a recipient of care were more likely to occur in spouses with lower esteem, and when greater amounts of help were received.

In a longitudinal design, Davey and Eggebeen (1998) studied elder parent and adult child dyads. These researchers also found that low relationship quality and not being able to reciprocate when receiving assistance predicted elder depression. Davey and Eggebeen suggested that elders operate under a norm of generalized reciprocity where exact repayment is not expected, and support provided when a parent's health was declining (contingent exchange) lessens depression.

In summary, researchers who studied reciprocity found that both dyad members benefited when they exchanged assistance, and that family care context (dyad's role relationship, quality of relationship) affected depression. The researchers who studied reciprocity recommended developing and testing interventions that target preventing negative interactions, providing elders with no more assistance than what is required, and providing opportunities to reciprocate when one received assistance.

\section{Characteristics of shared care identified in the literature}

In this review of selected literature, researchers identified important characteristics for the components of Shared Care. Characteristics important to communication were agreement and level of communication. Satisfaction and cohesion were identified as characteristics of decision-making. Also support, assistance, appreciation, and patterns of interpersonal exchange 
were identified as characteristics of reciprocity. These characteristics expand the understanding of the components of Shared Care as originally conceptualized.

These researchers also identified separate effects for the components of Shared Care on outcomes for both dyad members. However, no single study investigated all three components of Shared Care. The construct Shared Care extended previous conceptualizations of family care relationships by capturing three critical components: communication, decision-making, and reciprocity. I propose that Shared Care can modify the effects of providing and receiving assistance on the quality of the dyad's relationship. For example, when there are high demands for giving and receiving assistance and high Shared Care the quality of the dyad's relationship could be maintained or improved.

\section{The context for shared care}

For Shared Care to occur, certain conditions must be met. For example, individual prerequisites for communication are intact sensory channels and cognitive structures, and processes to comprehend, understand, and interpret language. In situations where an elder has a severe cognitive deficit, other family members may substitute for the elder and engage in communication, decision-making, and reciprocity. However, researchers have indicated that elders with mild to moderate cognitive impairment were able to answer questions about their own care and preferences with accuracy and reliability (Feinberg \& Whitlatch 2001).

Other cognitive factors influencing Shared Care are personal judgements about the motives and actions of another, self-esteem and self-concept. Researchers have shown that people form opinions about motives and actions of others even though these judgements may be misleading and inaccurate (Gayle \& Preiss 2002a). Regardless of accuracy, positive beliefs about a partner's motives enhance communication, whereas negative beliefs about another's motives act as barriers to communication. Self-concept also affects communication because people tend to communicate in ways that confirm their own identity and esteem. Taylor and Brown (1988) found that people process information in a manner that will enhance their self-concept, and tend to avoid and deny threatening information. Taylor posits that in social interactions people tend to solicit and receive self-confirming feedback.

The most obvious requirement for Shared Care is a dyad consisting of a person with a chronic illness requiring the assistance of a family member. Shared Care is a dyadic process, and dyadic processes are based on the premise that each participant affects and is affected by the other (Gayle \& Preiss 2002b). Gayle and Preiss suggested that the level of sharing in interpersonal relationships is an indicator of relationship maturity. These researchers believe 
interpersonal communication is affected by similarity in dyads' subjective perceptions, attitudes and goals. They described communication as a disclosure process by which one person verbally reveals information about thoughts, feelings, and experiences. Communication is facilitated when people's attitudes and beliefs are similar. Yet, even in cases of dissimilar attitudes, when people have a pleasant opportunity to interact, the aversive effects of dissimilar attitudes are moderated (AhYun 2003).

Other contextual factors influencing Shared Care are illness characteristics, and dyad goals for maintaining control and affiliation. Communication can result in agreement about goals and modify effects of dissimilar goals. Characteristics of illness conditions such as incomplete or conflicting beliefs about the illness, complex health decisions, short timelines, and lack of skills in handling conflict may present barriers to communication and decision-making (Poole \& Billingsley 1989, Leventhal et al. 1999).

In addition to individual and dyadic factors, another important influence on Shared Care is a family's history and patterns of interdependence. Families have experiences providing assistance to members, and developed patterns of communicating, decision-making, and reciprocity which are not easily changed (Gaugler et al. 2002). For example, family members may see themselves as primarily parents, spouses, friends or other relations. For some these relationships lead naturally to caring for each other because of the nature of belonging to a family with mutual concern for its members. However, for others, that may not be true. Past relationships, either positive or negative, will influence willingness to provide assistance in the present. A family's pattern of communication, decision-making, and reciprocity is usually entrenched and not easily changed. Families with a willingness to provide assistance to members in need may never the less lack the knowledge, skill, and/or ability to provide the care.

\section{How can Shared Care inform research and practice?}

The construct of Shared Care and supporting literature shows the importance of the dyad relationship in family care situations. Improving the quality of family relationships is an important clinical issue. Social relationships are a significant determinant of emotional and physical health (Rook et al. 2004), and family members are vital to achieving optimal outcomes for elders with chronic health conditions (Grady et al. 2000, Naylor et al. 2004, Rook et al. 2004).

\section{Application to practice}

Nurses can use Shared Care and the supporting research to re-conceptualize how they assess family dyads experiencing chronic illness. For example, the cargiving and receiving 
relationship could be assessed for sources of support and how the relationship enhances a sense of purpose for each member of the dyad. The nurse could use Shared Care to assess dyad communication, decision-making, and reciprocity skills and pinpoint strengths and difficulties dyads' have with these skills. For example, the dyad could have solid communication skills, but lack decision-making skills. Once problems with communication, decision-making and reciprocity are identified interventions could be tailored to assist in areas of difficulty.

A variety of interventions have been suggested by researchers that may help with areas of Shared Care difficulty. For example, if a dyad is having difficulty talking about an emotional topic, then communication skills such as how to talk about emotions and reframe displaced anger could be taught to both members of the dyad (Stone et al. 2000). If poor communication skills are contributing to disagreement about an elder's illness experience, then interventions could target increasing communication skills such as listening and perspective taking (Pruchno et al. 1997a, Lyons et al. 2002, Horowitz et al. 2004). Interventions found to improve communication and decision-making skills in other settings could be used with family dyads, such as providing concrete information about symptoms, how to interpret them, and actions to take in response to the symptoms (Johnson 1999).

Another source of disagreement might occur if an elder perceives high relationship reciprocity, while a family member perceives low levels. Interventions to resolve disagreement about reciprocity could be planned and implemented. For example the dyad could be coached to match assistance provided with an elder's requirements for assistance. When assistance is provided, the elder should be given opportunities to reciprocate (Newsom \& Schulz 1998, Wolff \& Agree 2004). In this way, the dyad could be encouraged to participate in care in a way that preserves their relationship and prevents strain.

Additional research will be beneficial to test the effects of Shared Care on outcomes for other nursing interventions. Shared Care could be an intervening variable which alters the effect of nursing interventions on patient outcomes. For example, high Shared Care in a dyad's relationship may contribute to agreement about their shared experience, how to respond to symptoms, and better self-care.

Measuring the construct Shared Care will capture important information about how a family process interacts with nursing interventions. However, before the effects of Shared Care can be tested, a measure of the construct is needed. A measure of Shared Care is currently being tested in two studies with elders receiving home health care and their family members. A psychometrically sound measure of Shared Care will advance research based on the construct. 
Future intervention research could target ways to bolster Shared Care skills in both members of the dyad to achieve optimal outcomes and control healthcare cost.

\section{Conclusion}

The definition of Shared Care identified in a previous study was further developed in this paper by examining how researchers used the concepts of communication, decision-making, and reciprocity to study family care. Review of selected literature supported the importance of the dyad's relationship on outcomes for both members of the dyad. Progress in the area of family care can be enhanced through the creation of a construct that captures effectively the interactive effect of the three components, communication, decision-making, and reciprocity. I proposed that Shared Care moderates the effects of giving and receiving assistance on the quality of the dyads relationship, and may intervene with other nursing interventions to affect outcomes of care. Shared care provides a structure to expand the view of family care to include both members of a care dyad and account for positive and negative aspects in the relationship.

\section{Acknowledgements}

I would like to acknowledge Drs Patti Brennan, Jean Johnson, and Beth Rodgers for their intellectual contributions to this manuscript. The Department Health and Human Service Public Health Service, National Institute Health, National Institute Nursing Research provided financial support for this study (grant T32 NR07102).

\section{References}

AhYun K. (2003) Similarity and attraction. In Interpersonal Communication Research: Advances Through Meta-Analysis (Allen M., Preiss R.W., Gayle B.M. \& Burrell N.A., eds), Lawrence Erlbaum, Mahwah, NJ, pp. 145-167.

Aneshensel C.S., Pearlin L.I., Mullan J.T., Zarit S.H. \& Whitlatch C.J. (1995) Profiles in Caregiving: The Unexpected Career. Academic Press, San Diego, CA.

Archbold P.G., Stewart B.J., Greenlick M.R. \& Harvath T.A. (1990) Mutuality and preparedness as predictors of caregiver role strain. Research in Nursing and Health 13, 375-384.

Archbold P.G., Stewart B.J., Greenlick M.R. \& Harvath T.A. (1992) The clinical assessment of mutuality and preparedness in family caregivers to frail older people. In Key Aspects of Elder Care (Funk S.G., Tornquist E.M., Champagne M.T. \& Copp L.A., eds), Springer, New York, pp. 328-339. 
Beach S.R., Schulz R., Yee J.L. \& Jackson S. (2000) Negative and positive health effects of caring for a disabled spouse: longitudinal findings from the caregiver health effects study. Psychology and Aging 15(2), 259-271.

Davey A. \& Eggebeen D.J. (1998) Patterns of intergenerational exchange and mental health. Journals of Gerontology Series B-Psychological Sciences and Social Sciences 53(2), 86-95.

Deimling G.T., Smerglia V.L. \& Schaefer M.L. (2001) The impact of family environment and decision-making satisfaction on caregiver depression: a path analytic model. Journal of Aging and Health 13(1), 47-71.

Donelan K., Hill C.A., Hoffman C., Scoles K., Feldman P.H., Levine C. \& Gould D. (2002) Challenged to care: informal caregivers in a changing health system. Health Affairs 21(4), 222-231.

Feinberg L.F. \& Whitlatch C.J. (2001) Are persons with cognitive impairment able to state consistent choices? Gerontologist 41(3), 374-382.

Gaugler J.E., Kane R.L. \& Kane R.A. (2002) Family care for older adults with disabilities: toward more targeted and interpretable research. International Journal of Aging and Human Development 54(3), 205-231.

Gayle B.M. \& Preiss R.W. (2002a) Chapter 3. An overview of individual processes in interpersonal communication. In Interpersonal Communication Research: Advances Through Meta- Analysis (Burrell N.A., ed.), Lawrence Erlbaum Associates, Mahwah, NJ, pp. 45-58.

Gayle B.M.\& Preiss R.W. (2002b) Chapter 7. An overview of dyadic processes in interpersonal communication. In Interpersonal Communication Research: Advances Through Meta-Analysis (Burrell N.A., ed.), Lawrence Erlbaum Associates, Mahwah, NJ, pp. 111124.

Germino B. (1991) Cancer and the family. In Cancer Nursing a Comprehensive Textbook (Baird S.B., McCorkle R. \& Grant M., eds), Saunders, Philadelphia, PA, pp. 38-44.

Grady K.L., Dracup K., Kennedy G., Moser D.K., Piano M., Stevenson L.W. \& Young J.B. (2000) Team management of patients with heart failure: a statement for healthcare professionals from the Cardiovascular Nursing Council of the American Heart Association. Circulation 102(19), 2443-2456.

Hooker K., Monahan D., Bowman S., Frazier L. \& Shifren K. (1998) Personality counts for a lot: predictors of mental and physical health of spouse caregivers in two disease groups. Journal of Gerontology: Psychological Sciences 53B(2), 73-85. 
Horowitz A., Goodman C. \& Reinhardt J. (2004) Congruence between disabled elders and their primary caregivers. The Gerontologist 44(4), 532-542.

Johnson J. (1999) Self-regulation theory and coping with physical illness. Research in Nursing and Health 22, 435-488.

Kellett U.M. (1998) Meaning-making for family carers in nursing homes. International Journal of Nursing Practice 4(2), 113-119.

Kellett U.M. (1999a) Searching for new possibilities to care: a qualitative analysis of family caring involvement in nursing homes. Nursing Inquiry 6(1), 9-16.

Kellett U.M. (1999b) Transition in care: family carers' experience of nursing home placement. Journal of Advanced Nursing 29(6), 1474-1481.

Kellett U.M. \& Mannion J. (1999) Meaning in caring: reconceptualizing the nurse-family carer relationship in community practice. Journal of Advanced Nursing 29(3), 697-703.

Leventhal H., Idler E. \& Leventhal E. (1999) The impact of chronic illness on self and identity. In Self, Social Identity, and Physical Health Interdisciplinary Explorations, Vol. 2 (Contrada R.J. \& Ashmore R.D., eds), Oxford University Press, New York, pp. 185- 208.

Liang J., Krause N.M. \& Bennett J.M. (2001) Social exchange and well-being: is giving better than receiving? Psychology and Aging 16(3), 511-523.

Lincoln Y.S. \& Guba E.G. (1985) Naturalistic Inquiry. Sage, Newbury Park, CA.

Lyons K.S., Zarit S.H., Sayer A.G. \& Whitlatch C.J. (2002) Caregiving as a dyadic process: perspectives from caregiver and receiver. Journals of Gerontology Series B-Psychological Sciences and Social Sciences 57(3), P195-P204.

Marks N.F., Lambert J.D. \& Jun H.J. (2001) The effects of transitions in filial caregiving on mental and physical health: a prospective US National Survey. Unpublished Manuscript, University of Wisconsin-Madison, Madison, WI.

Naylor M.D., Brooten D.A., Campbell R.L., Maislin G., McCauley K.M. \& Schwartz J.S. (2004) Transitional care of older adults hospitalized with heart failure: a randomized, controlled trial. Journal American Geriatric Society 52(5), 675-684.

Newsom J.T. (1999) Another side to caregiving: negative reactions to being helped. Current Directions in Psychological Science 8(6), 183-187.

Newsom J.T. \& Schulz R. (1998) Caregiving from the recipient's perspective: negative reactions to being helped. Health Psychology 17(2), 172-181.

Poole M.S. \& Billingsley J. (1989) The structuring of dyadic decisions. In Dyadic Decision Making (Brinberg D. \& Jaccard J., eds), Springer-Verlag, New York, pp. 216-248. 
Pruchno R.A., Burant C.J. \& Peters N.D. (1997a) Typologies of caregiving families: family congruence and individual well-being. Gerontologist 37(2), 157-167.

Pruchno R.A., Burant C.J. \& Peters N.D. (1997b) Understanding the well-being of care receivers. Gerontologist 37(1), 102-109.

Reinardy J.R., Kane R.A., Huck S., Call K.T. \& Shen C.T. (1999) Beyond burden - two ways of looking at caregiving burden. Research on Aging 21(1), 106-127.

Rook K., Sorkin D. \& Zettel L. (2004) Stress in social relationships. In Growing Together: Personal Relationships Across the Life Span (Lang F.R. \& Fingerman K.L., eds), Cambridge University Press, New York, pp. 210-239.

Schwartz-Barcott D. \& Kim H.S. (1993) An expansion and elaboration of the Hybrid Model of Concept Development. In Concept Development in Nursing: Foundations, Techniques, and Applications (Rodgers B.L. \& Knafl K.A., eds), W.B. Saunders, Philadelphia, PA, pp. 107-133.

Schwartz-Barcott D. \& Kim H.S. (2000) An expansion and elaboration of the Hybrid Model of Concept Development. In Concept Development in Nursing: Foundations, Techniques, and Applications, 2nd edn (Rodgers B.L. \& Knafl K.A., eds), W.B. Saunders, Philadelphia, PA, pp. 129-159.

Sebern M. (1996) Explication of the construct of shared care and the prevention of pressure sores in home health care. Research in Nursing and Health 19, 183-192.

Smerglia V.L. \& Deimling G.T. (1997) Care-related decision-making satisfaction and caregiver well-being in families caring for older members. Gerontologist 37(5), 658-665.

Stone D., Patton B. \& Heen S. (2000) Difficult Conversations How to Discuss What Matters Most. Penguin Books, New York.

Taylor S.E. \& Brown J. (1988) Illusion and well-being: a social psychological perspective on mental health. Psychological Bulletin 103, 193-210.

Thomas V.\& Ozechowski T.J. (2000) A test of the circumplex model of marital and family systems using the Clinical Rating Scale. Journal of Marital and Family Therapy 26(4), 523-534.

Walker A.J., Pratt C.C. \& Oppy N.C. (1992) Perceived reciprocity in family caregiving. Family Relations 41(1), 82-85.

Wolff J.L. \& Agree E.M. (2004) Depression among recipients of informal care: the effects of reciprocity, respect, and adequacy of support. Journals of Gerontology Series B-Psychological Sciences and Social Sciences 59(3), S173-S180. 
World Health Organization (2004) Home Based Long Term Care, retrieved 24 November 2004, available at: http://www.who.int/ chronic_conditions/ltc/en/print.html. 


\section{Appendix}

\section{Table 1: Summary of related research}

\begin{tabular}{|c|c|c|}
\hline Reference & Sample/design & Findings \\
\hline $\begin{array}{l}\text { Archbold et al. } \\
\qquad(1990)\end{array}$ & $\begin{array}{l}n=78 \text { dyads (care receiver and } \\
\text { giver). Longitudinal study of } \\
\text { effects of mutuality on care } \\
\text { giver role strain }\end{array}$ & $\begin{array}{l}\text { Mutuality was associated with lower levels of caregiver role for some but not all } \\
\text { aspects of role strain. Mutuality accounted for statistically significant } \\
\text { increments in } R^{2} \text {. When mutuality higher strain from direct care, increased } \\
\text { tension, and global strain lower. }\end{array}$ \\
\hline $\begin{array}{l}\text { Pruchno et al. } \\
\qquad(1997 a)\end{array}$ & $\begin{array}{l}n=252, \text { Female primary } \\
\text { Caregivers, husbands, and } \\
\text { children living in households. } \\
\text { Cross-sectional design }\end{array}$ & $\begin{array}{l}\text { Families rated as high in their agreement about patient problem behaviours, had } \\
\text { less burden }(F=20.76, P<.0 .01) \text { and depression }(F=5.74, P<0.01) \text {, and } \\
\text { higher satisfaction }(F=9.59, P<0.01) \text { and mastery }(F=8.19, P<0.01)\end{array}$ \\
\hline $\begin{array}{l}\text { Pruchno et al. } \\
\quad(1997 b)\end{array}$ & $\begin{array}{l}n=129, \text { Elder over } 60 \text { years } \\
\text { living in multi-generation } \\
\text { household }\end{array}$ & $\begin{array}{l}\text { Elder providing assistance to family (advice, emotional support) predicted higher } \\
\text { personal control (extent one can influence events in life) } \\
\text { Personal control and better positive affect predicted depression }\left(x^{2}=7 \cdot 2 \text {, d.f. } 6 \text {, }\right. \\
P=0.297 \text {, goodness-of-fit index } 0.98)\end{array}$ \\
\hline $\begin{array}{l}\text { Smerglia and } \\
\text { Deimling } \\
(1997)\end{array}$ & $\begin{array}{l}n=244, \text { Caregivers } \\
\text { Cross-sectional interviews part of } \\
\text { a larger longitudinal study }\end{array}$ & $\begin{array}{l}\text { Family environment operationalized as adaptability }(\beta=0.26, P<0.00) \text { and } \\
\text { conflict }(\beta=-0.25, P<0.01) \text {, predicted decision-making satisfaction } \\
\text { Adaptability }(\beta=-0.23, P<0.00) \text { and decision-making satisfaction }(\beta=-0.16, P \\
\quad<0.02) \text {, predicted caregiver depression }\end{array}$ \\
\hline $\begin{array}{l}\text { Davey and } \\
\text { Eggebeen } \\
(1998)\end{array}$ & $\begin{array}{l}n=2237, \text { Elder parent dyads } \\
\text { over } 50 \text { years } \\
\text { Longitudinal two waves of data } \\
\text { collection }\end{array}$ & $\begin{array}{l}\text { Contingent exchange (receive greater amount of support with decline in health) } \\
(B=-0.59, P<0.0001) \text {, having a better relationship }(B=-0.08 P<0.01) \text {, and } \\
\text { receiver less instrumental support }(B=0.341, P<0.001) \text {, predicted level of } \\
\text { patient depression } \\
\text { Social exchange hypothesis not supported in that if parent over benefited then } \\
\text { parent had higher levels of depression }(B=0.248, P<0.05) \\
\text { Moderating effect for contingent support, if support received in context of decline } \\
\text { in health fewer depressive symptoms }(B=0.187, P<0.05)\end{array}$ \\
\hline Kellett (1998) & $\begin{array}{l}\text { Hermeneutic analysis explore } \\
\text { experience of } 14 \text { family carers } \\
\text { in nursing home }\end{array}$ & Family involvement in care provides meaning to their existence \\
\hline $\begin{array}{l}\text { Newsom and } \\
\text { Schulz (1998) }\end{array}$ & $\begin{array}{l}n=276, \text { Elders, recipients of } \\
\text { care, living with spouse } \\
\text { Longitudinal design }\end{array}$ & $\begin{array}{l}\text { Lower self-esteem, fatalism, and high amounts of assistance predicted helping } \\
\text { distress operationalized as emotional strain experienced in response to } \\
\text { receiving assistance with ADLs } \\
\text { Helping distress predicted recipient of care depression currently }(\beta=0.44, P< \\
0.001) \text { and in } 1 \text { year }(\beta=0.19, P<0.01) \text {. ADL/IADL predicted recipient of care } \\
\text { depression in } 1 \text { year }(\beta=-0.14, P<0.05)\end{array}$ \\
\hline Kellett (1999a) & $\begin{array}{l}\text { Hermeneutic analysis } 14 \text { family } \\
\text { carers in nursing homes }\end{array}$ & $\begin{array}{l}\text { Found carer looks for new possibilities for care } \\
\text { Transition to nursing homes did not end carers need to care because of } \\
\text { meaning, value, feeling self-worth and purpose are important to one's identity }\end{array}$ \\
\hline Kellett (1999b) & $\begin{array}{l}\text { Hermeneutic analysis, } 14 \text { family } \\
\text { care givers for person with } \\
\text { dementia transitioning to } \\
\text { nursing homes }\end{array}$ & $\begin{array}{l}\text { Family caring activities prior to nursing homes provided a sense of meaning and } \\
\text { purpose, actions provide sense of usefulness and control over situation. } \\
\text { Experience of placement involved awareness of loss and being out of control. } \\
\text { Nurse should assist carer to recognize their worth and contributions to the } \\
\text { quality of experience of a family member }\end{array}$ \\
\hline $\begin{array}{c}\text { Kellett and } \\
\text { Mannion } \\
(1999)\end{array}$ & $\begin{array}{l}\text { Hermeneutic analysis, seven } \\
\text { family carers at home }\end{array}$ & $\begin{array}{l}\text { Caring is a human relating process which fosters family's meaningful } \\
\text { involvement in care, exchange of expertise and values, and provided sense of } \\
\text { worth based on expertise in care. Self-growth assisted person to find } \\
\text { continued meaning and developed skills to manage situation. Family members } \\
\text { have a need and desire to be involved in providing care to older relative }\end{array}$ \\
\hline
\end{tabular}




\begin{tabular}{|c|c|c|}
\hline Reference & Sample/design & Findings \\
\hline $\begin{array}{l}\text { Beach et al. } \\
\quad(2000)\end{array}$ & $\begin{array}{l}n=680, \text { Caregivers and matched } \\
\text { controls. Longitudinal design }\end{array}$ & $\begin{array}{l}\text { Caregiver strain predicted decreased perceived health }(\beta=-0.14, P<0.05) \text {, } \\
\text { increased depressive symptoms }(\beta=0.15, P<0.001) \text { and increased anxiety } \\
(\beta=0.17, P<0.001) \\
\text { Increase in spouse ADL impairment increased health risk behavior }(\beta=0.08, P \\
<0.05) \text { and anxiety }(\beta=0.10, P<0.01) \\
\text { Increased help provided to spouse predicted less depressive symptoms }(\beta= \\
0.08, P<0.05) \text { and anxiety }(\beta=-0.08, P<0.05)\end{array}$ \\
\hline $\begin{array}{l}\text { Deimling et al. } \\
\qquad(2001)\end{array}$ & $\begin{array}{l}n=244, \text { Caregivers } \\
\text { cross-sectional interviews part of } \\
\text { a larger longitudinal study }\end{array}$ & $\begin{array}{l}\text { Family environment operationalized as adaptability }(\beta=0.26, P<0.01) \text {, conflict } \\
(\beta=-0.25, P<0.001) \text {, and patient cognitive impairment }(\beta=-0.12, P<0.05) \\
\text { predicted decision-making satisfaction } \\
\text { Decision-making satisfaction }(\beta=-0.18, P<0.01) \text {, adaptability }(\beta=-0.26, P< \\
0.01) \text { and caregiver type (spouse) }(\beta=0.27, P<0.01) \text {, predicted caregiver } \\
\text { depression. }\end{array}$ \\
\hline $\begin{array}{l}\text { Thomas and } \\
\text { Ozechowski } \\
(2000)\end{array}$ & $\begin{array}{l}n=70 \text { married couples mean age } \\
35 \cdot 6 \text { years }\end{array}$ & $\begin{array}{l}\text { Family functioning directly related to levels of cohesion, and indirectedly related } \\
\text { to levels of communication }\end{array}$ \\
\hline $\begin{array}{l}\text { Liang et al. } \\
\qquad(2001)\end{array}$ & $\begin{array}{l}n=827, \text { Elders in role of both } \\
\text { recipient and provider of } \\
\text { support }\end{array}$ & $\begin{array}{l}\text { Giving support predicted increase in negative interaction }(\beta=0.46, P<0.001) \\
\text { and had a positive effect on anticipate support }(\beta=0.15, P<0.01) \\
\text { Giving support did not affect depression (total effect }=0.01, P>0.05) \\
\text { Elder depression predicted by negative interactions }(\beta=0.17, P<0.001) \text {, and } \\
\text { over benefiting in social exchanges }(\beta=0.12, P<0.05) \\
\text { Elder depression less with more anticipated support }(\beta=-0.17, P<0.001 \text { ) and } \\
\text { under benefiting in social exchanges }(\beta=-0.12, P<0.05)\end{array}$ \\
\hline $\begin{array}{l}\text { Lyons et al. } \\
\qquad(2002)\end{array}$ & $\begin{array}{l}n=63, \text { Caregiving dyad unit of } \\
\text { analysis } \\
\text { Cross-sectional design }\end{array}$ & $\begin{array}{l}\text { Care giver relationship strain predicted care difficulty mean score }(\mathrm{B}=0.29, P< \\
0.000) \text { and dyad discrepancy about care difficulty }(\mathrm{B}=0.25 \mathrm{P}<0.002) \\
\text { Care giver relationship strain correlated with caregiver negative health }(r=0.47 \\
P<0.0001) \text { and depression }(r=0.52, P<0.0001)\end{array}$ \\
\hline $\begin{array}{l}\text { Horowitz et al. } \\
\qquad(2004)\end{array}$ & $\begin{array}{l}n=117 \text { visually impaired elders } \\
\text { and family care giver. } \\
\text { Cross-sectional correlation } \\
\text { study of effects of dyad } \\
\text { congruence }\end{array}$ & $\begin{array}{l}\text { Measured four congruence domains (functional status, overprotective, disease } \\
\text { knowledge, adaptation). Caregiver depression associated with incongruence } \\
\text { about adaptation to vision loss (caregiver: } \beta=0 \cdot 14, P<0 \cdot 08 \text { ). } \\
\text { Lower caregiver depression associated greater incongruence in over protection } \\
\text { (caregiver: } \beta=-0 \cdot 26, P<0.07 \text { ). } \\
\text { Elder's functional status and quality of relationship consistently influenced } \\
\text { congruence }\end{array}$ \\
\hline $\begin{array}{l}\text { Wolf and Agree } \\
\text { (2004) }\end{array}$ & $\begin{array}{r}n=226 \text { dyads participated in six } \\
\text { interviews. Prospective survey }\end{array}$ & $\begin{array}{l}\text { Individual was } 33-36 \% \text { more likely to be depressed if not asked for advice }(P< \\
0.05) \\
\text { Individuals in more reciprocal relationship and in relationships feel respected } \\
\text { and loved are likely to be less depressed }\end{array}$ \\
\hline
\end{tabular}

\section{Sebern 18}


Figure 1: Shared Care construct

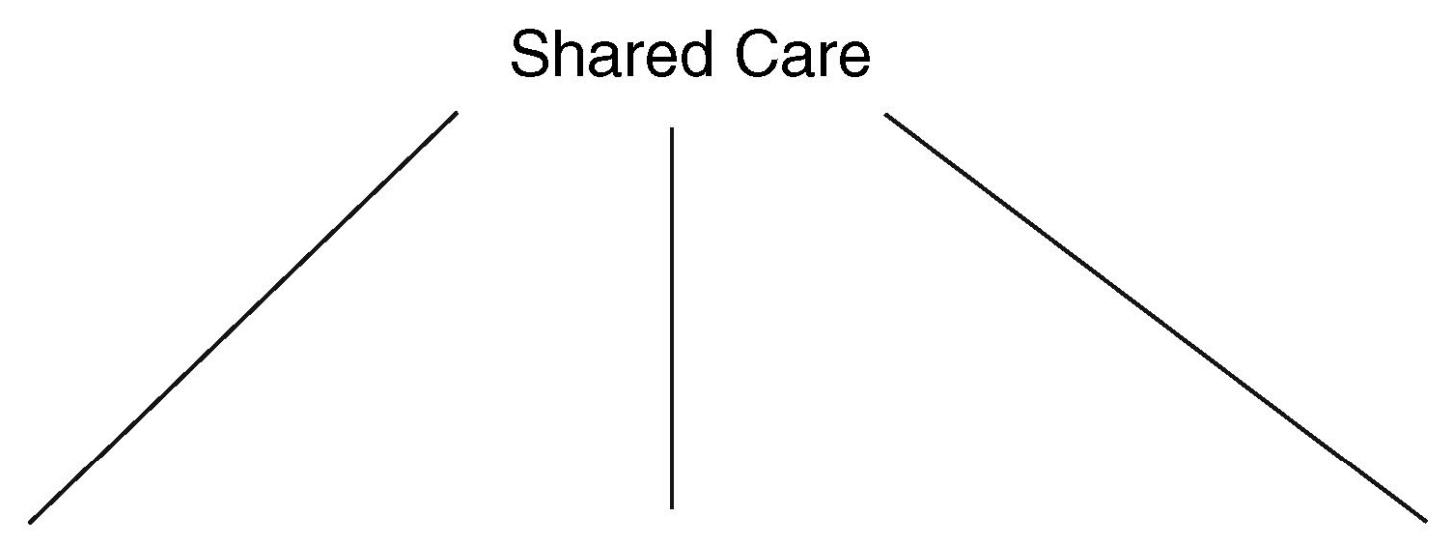

Communication

Decision-making

Reciprocity

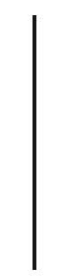

$$
\mid
$$

Examples of content:

- Signs \& symptoms

- Feelings

- Information
Examples of content:

- Seeking information

- Involvement in decisions
Examples of content:

- Empathy

- Listening

- Partners 


\section{Overview}

\section{What is already known about this topic}

- The characteristics and unique importance of communication, decision-making, and reciprocity in family care are communication about the shared chronic illness experience, decision-making about how to respond to the illness, and partnership in care activities.

\section{What this paper adds}

- Confirmation of the importance of the dyad relationship in family care (care-giving and -receiving situations).

- Extension of previous conceptualizations of family care by capturing three critical components: communication, decision-making and reciprocity.

- A structure to expand conceptualization of family care to include both members of a care dyad and account for positive and negative aspects. 